\title{
Low density lipoprotein cholesterol is inversely correlated with abdominal visceral fat area: a magnetic resonance imaging study
}

\author{
Michel R Hoenig ${ }^{1 *}$, Gary Cowin², Raymond Buckley ${ }^{3}$, Christine McHenery ${ }^{3}$, Allan Coulthard ${ }^{3}$
}

\begin{abstract}
Background: Visceral Fat Area (VFA) is an independent predictor of coronary disease. While low density lipoprotein cholesterol (LDL-C) is used to determine risk and guide therapy, its accuracy fails in obese patients who may have low LDL-C despite high VFA.

Objective: We sought to describe the relationship between VFA, LDL-C and to describe shifting cholesterol metabolism with increasing VFA.

Methods: 42 High-risk vascular patients not on lipid-lowering therapy provided a fasting lipid profile and underwent magnetic resonance imaging (MRI) to quantify VFA and subcutaneous fat area (SFA) at the L4-L5 disc. Comparisons: 1. Correlation between VFA, SFA, LDL-C and the standard lipid panel 2. Correlation between VFA, SFA and markers of cholesterol synthesis (desmosterol, lathosterol) and cholesterol absorption (cholestanol, sitosterol).

Results: VFA was inversely correlated with LDL-C $(r=-0.348)$ indicating potential discordance between cardiovascular risk and LDL-C. However, VFA was appropriately correlated with other markers of increased risk: $r=$ -0.361 with HDL-C, $r=0.503$ with VLDL-C, $r=0.499$ with TG (all $p<0.05$ ). VFA did not correlate significantly with non-HDL-C. VFA correlated positively with cholesterol synthesis markers (desmosterol, lathosterol) and negatively with an absorption marker (cholestanol).

Conclusions: LDL-C is inversely correlated with VFA and this may explain the loss of the relationship between LDL-C and cardiovascular events in the obese. While Non-HDL-C did not correlate positively with VFA, the absence of a negative correlation suggests that it may be a more appropriate lipid target in an increasingly obese world.
\end{abstract}

\section{Introduction}

Visceral fat area (VFA), measured at the umbilicus, has been independently linked to the development of coronary artery disease (CAD) while subcutaneous fat area (SFA) has not been shown to carry prognostic significance [1]. The accumulation of visceral adipose tissue is associated with the adverse metabolic consequences of obesity and VFA is a better predictor of cardiovascular risk factors than body mass index (BMI), even in nonobese individuals [1-6]. However, in determining patient risk and tailoring therapy, clinicians rarely quantify fat areas using imaging modalities and typically rely on the

\footnotetext{
* Correspondence: drmhoenig@yahoo.com.au

'Royal Brisbane and Women's Hospital, University of Queensland Centre for

Clinical Research, Brisbane, Queensland, Australia

Full list of author information is available at the end of the article
}

standard lipid panel. The current target of therapy is low density lipoprotein cholesterol (LDL-C) which shows a log-linear relationship with cardiovascular events in both primary and secondary prevention [7]. However, several reports have highlighted the loss of the relationship between LDL-C and subsequent cardiovascular events, as reviewed previously [6]. In a cohort from the Lipid Research Clinics prevalence study, men with LDL-C $<100 \mathrm{mg} / \mathrm{dl}$, had an increased cardiovascular mortality when compared to men with LDL-C in the $100-130 \mathrm{mg} / \mathrm{dl}$ range and hence the log-linear relationship between LDL-C and coronary events appears invalid, especially in patients with high triglycerides (TG) $>200 \mathrm{mg} / \mathrm{dl}$ [8]. Similarly, an analysis of diabetic patients (average TG $254 \mathrm{mg} / \mathrm{dl}$ ) also suggests a dissociation between CAD death and LDL-C [9]. In a large cohort of

\section{Biomed Central}


patients with CAD, diabetes was identified as a predictor of lower LDL-C levels; despite diabetics being at higher risk for cardiovascular events [10]. Indeed, the epidemiological studies on the basis of which the Adult Treatment Panel III (ATPIII) formulated guidelines were from an era when diabetes, obesity and the metabolic syndrome were less prevalent [6].

LDL-C has been criticized as a target of therapy that does not take into account very low-density lipoprotein cholesterol (VLDL-C) which predicted coronary events independently of LDL-C in the Framingham cohort [11]. The current ATPIII guidelines only recommend the consideration of the VLDL-C fraction in patients with hypertriglyceridemia. Non-High density lipoprotein cholesterol (non-HDL-C), calculated as total cholesterol minus high density lipoprotein cholesterol (TC - HDLC) is recommended as a secondary target of therapy in patients with TG $>200 \mathrm{mg} / \mathrm{dl}$ and takes into account the VLDL-C fraction [12]. However, non-HDL-C is superior to LDL-C in predicting CAD events regardless of whether TG is greater than or less than $200 \mathrm{mg} / \mathrm{dl}$ $[6,11]$. In order to more accurately assess the relationship between obesity and the lipid panel, we sought to describe the relationship between VFA, SFA, LDL-C, VLDL-C and non-HDL-C. Since increasing levels of VLDL-C are associated with increasing hepatic cholesterol synthesis $[13,14]$, we also related VFA and SFA to cholesterol synthesis markers (desmosterol, lathosterol) and cholesterol absorption markers (cholestanol and sitosterol) to determine the relationship between cholesterol metabolism and visceral adiposity.

\section{Methods \\ Study Population}

We recruited patients with established vascular disease into this study. All patients had documented coronary artery disease (CAD), ischemic stroke or CAD riskequivalents and thus represented a high-risk cohort eligible for aggressive lipid-lowering therapy. Eligible patients had to have at least one of the following: 1 . CAD (positive angiogram or history of myocardial infarction) 2. peripheral vascular disease $(\mathrm{ABI}<0.9$ or history of lower limb revascularization for atherosclerosis) 3. abdominal aortic aneurysm 4. carotid atherosclerosis with $>50 \%$ narrowing 5 . type II diabetes with age $>50$ and 3 additional risk factors (male sex, albuminuria, hypertension, HDL-C $<40 \mathrm{mg} / \mathrm{dl}$, TG $>150 \mathrm{mg} / \mathrm{dl}$, LDL-C $>100 \mathrm{mg} / \mathrm{dl}$, current smoking, diabetes duration $>20$ years) or 6 . ischemic stroke. Study participants were in a clinically stable condition and were recruited from the vascular surgery outpatient department at the Royal Brisbane \& Women's Hospital (RBWH). To ensure accurate assessment of endogenous cholesterol metabolism, patients treated with any statin, ezetimibe or stanol/sterol spreads at baseline were excluded. This study is approved by the RBWH research ethics committee (2005/006A) and all study participants gave informed consent.

\section{Patient Data}

Patient demographic information was collected including age, sex, qualifying criterion, self-reported race, height, weight, waist and hip circumferences. Fasting blood samples were analyzed for baseline lipids, glucose, insulin, high sensitivity C-reactive protein (CRP), cholestanol, sitosterol, desmosterol and lathosterol. To determine insulin sensitivity, we used the Quantitative insulin sensitivity check index (QUICK Index) since this a superior linear correlate $(\mathrm{r} \sim 0.8-0.9)$ of the reference standard glucose clamp than the Homeostasis model assessment (HOMA) model $[15,16]$.

\section{MRI Measurement of Abdominal Fat Areas}

MR imaging was performed with a Siemens Trio $3 \mathrm{~T}$ MRI system (Erlangen, Germany) using standard array coils with the subject supine. Breath-hold FISP images were centered on the L4-L5 intervertebral disc using standard localizer images with the following parameters: $\mathrm{TR}=4 \mathrm{~ms}, \mathrm{TE}=2 \mathrm{~ms}$, number of slices $=12$, slice thickness $=8 \mathrm{~mm}$, image matrix $256 \times 256$, field-ofview $=500 \times 500 \mathrm{~mm}$. The 4 slices that were best aligned with the L4-L5 disc $(19,20)$, were analyzed by a single operator $(\mathrm{MRH})$ using the polygon region of interest in Escape Medical Viewer v3.2 to define visceral fat area (VFA) and subcutaneous fat area (SFA) as described previously [17]. Briefly, VFA and SFA were measured by fitting a spline curve to points on the border of the subcutaneous and visceral regions. Nonfat regions within the visceral region were also outlined with a spline fit and subtracted from the total visceral region.

\section{Laboratory Methodology}

Fasting lipid profile was determined using standard hospital methods and LDL-C was indirectly measured using the Friedewald method. CRP was determined by highsensitivity immunonephelometry. Insulins were measured by Chemilumnescent Immunoassay on a Beckman Coulter DxI800 as per the manufacturer's instructions. Cholestanol, sitosterol, desmosterol and lathosterol were measured using gas chromatography/mass spectrometry (GCMS) (Agilent, Model 6890/ 5973 using Chemstation software). Internal standards were 5 - $\alpha$-cholestane for cholestanol, D7 sitosterol for sitosterol and D4 lathosterol for both lathosterol and desmosterol. Plasma (50 $\mu \mathrm{L}$ ) was assayed with the addition of internal standards. The sample was then saponified at 60 degrees Celsius for 60 minutes using potassium hydroxide and extracted 
three times with hexane, each time centrifuging and combining organic layers. Combined organic layers were dried under nitrogen and the residue derivatised with bistrimethylsilyl trifluoroacetic anhydride/ 1\% trimethylchlorosilane (BSTFA/TMCS) to form trimethylsilyl derivatives. The final derivatised extract $(1 \mu \mathrm{L})$ was injected into the GCMS system and sterols separated using a capillary column DB 5 MS type (length $30 \mathrm{~m}, 0.25 \mathrm{~mm}$ internal diameter and 0.25 micron film thickness). Diagnostic ions specific for cholestanol, sitosterol, desmosterol, lathosterol and internal standards were monitored and the ratio of the sterol target ions to their respective internal standard ions was calculated and related to a calibration curve. The calibration curve was based on spiked normal plasma corrected for endogenous sterol levels using the technique of standard addition. Inter and intra-run coefficients of variation were $5 \%$ and $3 \%$ respectively. Linearity $\left(\mathrm{r}^{2}=0.998\right)$ was established beyond physiological values.

\section{Statistical Methods}

The QUICK Index of insulin sensitivity for each subject was calculated as $1 /[\log$ (fasting insulin, $\mu \mathrm{U} / \mathrm{ml}$ ) $+\log$ (fasting glucose, $\mathrm{mg} / \mathrm{dl}$ )] [15]. We first undertook univariate correlation with VFA or SFA as the dependent variable and the baseline fasting lipid panel, fasting glucose, fasting insulin and QUICK Index as independents. Skewed distributions were log-transformed. This was followed by correlations between VFA, SFA and various markers of cholesterol metabolism. All analyses were done with statistics software (SPSS 16).

\section{Results}

Forty three patients were enrolled in this study. One patient was removed from this analysis because of hypertriglyceridemia (TG $>400 \mathrm{mg} / \mathrm{dl}$ ), rendering indirect methods of LDL-C determination inaccurate leaving 42 patients in this analysis. Baseline characteristics, including baseline lipid panel, CRP, cholesterol synthesis markers (lathosterol, desmosterol) and cholesterol absorption markers (cholestanol, sitosterol) were available in all patients. The baseline characteristics of the 42 patients who are included in this analysis are shown in Table 1. Summary statistics for the baseline lipid panel and cholesterol metabolism markers are shown in Table 2. In order to explore the relationship between visceral fat area (VFA), subcutaneous fat area (SFA) and metabolic parameters, we undertook univariate correlation between VFA, SFA and components of the lipid panel, CRP, fasting glucose, insulin and the QUICK Index of insulin sensitivity. The results of univariate correlation are shown in Table 3. Concordant with previous reports, VFA is a more consistent correlate of metabolic parameters than SFA. SFA was not significantly
Table 1 Patient Characteristics of Patients Included in the Analysis

\begin{tabular}{ll}
\hline & Mean \pm SD or $\mathbf{n}$ (\%) \\
\hline Age & $70 \pm 8$ \\
\hline Males & $34(81)$ \\
\hline Females & $8(19)$ \\
\hline Race & $41(98)$ \\
\hline \multicolumn{1}{|c}{ White } & $1(2)$ \\
\hline Non-White & $172 \pm 10$ \\
\hline Height (cm) & $78 \pm 19$ \\
\hline Weight (kg) & $26 \pm 5$ \\
\hline Body Mass Index & $101 \pm 16$ \\
\hline Waist (cm) & $101 \pm 13$ \\
\hline Hip (cm) & $10(24)$ \\
\hline Diabetic & $22(52)$ \\
\hline Metabolic Syndrome by ATP III Criteria & $115 \pm 37$ \\
\hline Fasting Glucose (mg/dl) & $7 \pm 4$ \\
\hline Fasting Insulin (mU/L) & $.25 \pm .02$ \\
\hline QUICK & $202 \pm 112$ \\
\hline Visceral Fat Area (cm²) & $239 \pm 115$ \\
\hline Subcutaneous Fat Area (cm ${ }^{2}$ ) & $45 \pm 12$ \\
\hline Percent Visceral Fat Area & $10(24)$ \\
\hline Qualifying Criterion* & $23(55)$ \\
\hline \multicolumn{1}{c}{ Coronary Artery Disease } & $10(29)$ \\
\hline Peripheral Vascular Disease & $10(24)$ \\
\hline Carotid Atherosclerosis $>50 \%$ & \\
\hline Ischemic Stroke & \\
\hline Diabetes & \\
\hline Patients frequently had $>1$ inclusion criterion & \\
\hline
\end{tabular}

*Patients frequently had $>1$ inclusion criterion.

correlated to VLDL-C, triglycerides or fasting glucose. Hence, in our cohort, VFA overall appears a superior correlate to the adverse metabolic consequences of obesity. A noteworthy finding was the significant negative correlation between LDL-C and VFA ( $r=-0.348, \mathrm{p}=$ 0.024). Hence, while higher VFA has been independently associated with an increased risk of CAD, VFA is inversely correlated to LDL-C and thus patients with higher amounts of VFA may have lower LDL-C. Hence, this might explain the 'disconnect' between LDL-C and subsequent clinical events observed in patients with diabetes and hypertriglyceridemia $[6,8,11]$.

Moreover, VFA was a strong positive correlate of VLDL$C$ which is predictive of coronary events independently of LDL-C $[6,11]$. VLVL-C is not routinely considered for risk assessment in the current ATPIII guidelines. Since increasing VLDL-C is indicative of increased hepatic synthesis of cholesterol, we tested this more formally by assessing the relationships between VFA, SFA and cholesterol synthesis markers (desmosterol, lathosterol) and 
Table 2 Summary Population Lipids and CRP at Baseline

\begin{tabular}{ll}
\hline & $\begin{array}{l}\text { Baseline value } \\
\text { (mean } \pm \text { SD) }\end{array}$ \\
\hline Total Cholesterol $(\mathrm{mg} / \mathrm{dl})$ & $212 \pm 34$ \\
\hline $\mathrm{LDL}$ cholesterol $(\mathrm{mg} / \mathrm{dl})$ & $138 \pm 33$ \\
\hline $\mathrm{HDL}$ cholesterol $(\mathrm{mg} / \mathrm{dl})$ & $45 \pm 16$ \\
\hline Non-HDL cholesterol $(\mathrm{mg} / \mathrm{dl})$ & $167 \pm 33$ \\
\hline VLDL cholesterol & $29 \pm 14$ \\
\hline Triglycerides $(\mathrm{mg} / \mathrm{dl})$ & $146 \pm 72$ \\
\hline CRP $(\mathrm{mg} / \mathrm{L})$ & $3.53 \pm 2.47$ \\
\hline Cholestanol $(\mu \mathrm{mol} / \mathrm{L})$ & $7.03 \pm 2.73$ \\
\hline Desmosterol $(\mu \mathrm{mol} / \mathrm{L})$ & $2.77 \pm 0.94$ \\
\hline Lathosterol $(\mu \mathrm{mol} / \mathrm{L})$ & $5.88 \pm 3.18$ \\
\hline Sitosterol $(\mu \mathrm{mol} / \mathrm{L})$ & $6.31 \pm 3.65$ \\
\hline $\begin{array}{l}\text { Cholestanol:cholesterol ratio }(\mu \mathrm{mol} \text { cholestanol/ } \\
\text { mmol cholesterol } \times 100)^{*}\end{array}$ & $126 \pm 40$ \\
\hline $\begin{array}{l}\text { Desmosterol:cholesterol ratio }(\mu \mathrm{mol} \text { desmosterol/ } \\
\text { mmol cholesterol } \times 100)\end{array}$ & $51 \pm 16$ \\
\hline
\end{tabular}

Lathosterol:cholesterol ratio ( $\mu$ mol lathosterol/ $109 \pm 62$ mmol cholesterol $\times 100$ )

Sitosterol:cholesterol ratio $(\mu \mathrm{mol}$ sitosterol $/ \mathrm{mmol} \quad 112 \pm 57$ cholesterol $\times 100$ )

*this format is adopted for ease of comparison with previous reports; synthesis and absorption markers are standardized to total cholesterol.

cholesterol absorption markers (cholestanol and sitosterol). The results of this analysis are shown in Table 4. While neither VFA nor SFA correlated with sitosterol (an absorption marker), VFA correlated negatively with cholestanol (an absorption marker) and positively with synthesis makers desmosterol and lathosterol or their ratios. Hence, VFA is consistently associated with another

Table 3 Univariate Correlations of Visceral Fat Area, Subcutaneous Fat Area with Components of the Lipid Panel, Glucose, Insulin and the QUICK Index

\begin{tabular}{lll}
\hline & $\begin{array}{l}\text { Visceral Fat Area; } \\
\text { Pearson's r, (p-value) }\end{array}$ & $\begin{array}{l}\text { Subcutaneous Fat Area; } \\
\text { Pearson's r, (p-value) }\end{array}$ \\
\hline $\begin{array}{l}\text { Total } \\
\text { Cholesterol }\end{array}$ & $-.306(.049)$ & $-.142(.370)$ \\
\hline LDL & $-.348(.024)$ & $-.068(.668)$ \\
Cholesterol & & $-.339(.028)$ \\
\hline HDL & $-.361(.019)$ & $.029(.857)$ \\
Cholesterol & & \\
\hline $\begin{array}{l}\text { Non-HDL } \\
\text { Cholesterol }\end{array}$ & $-.139(.381)$ & $.217(.168)$ \\
\hline VLDL & $.503(.001)$ & $.226(.151)$ \\
Cholesterol & & $.000(.995)$ \\
\hline Triglycerides & $.499(.001)$ & $.111(.486)$ \\
\hline CRP & $.111(.484)$ & $.682(<.001)$ \\
\hline Fasting & $.522(<.001)$ & $-.592(<.001)$ \\
Glucose & &
\end{tabular}

Table 4 Univariate Correlations of Visceral Fat Area, Subcutaneous Fat Area and Markers of Cholesterol Synthesis (Desmosterol, Lathosterol) and Cholesterol Absorption (Cholestanol, Sitosterol)

\begin{tabular}{lll}
\hline & $\begin{array}{l}\text { Visceral Fat Area; } \\
\text { Pearson's r, (p-value) }\end{array}$ & $\begin{array}{l}\text { Subcutaneous Fat Area; } \\
\text { Pearson's r, (p-value) }\end{array}$ \\
\hline Cholestanol & $-.433(.004)$ & $-.270(.084)$ \\
\hline $\begin{array}{l}\text { Cholestanol: } \\
\text { Cholesterol ratio; } \\
\text { CCR }\end{array}$ & $-.357(.020)$ & $-.236(.132)$ \\
\hline Desmosterol & $.264(.092)$ & $.158(.317)$ \\
\hline $\begin{array}{l}\text { Desmosterol: } \\
\text { cholesterol ratio; }\end{array}$ & $.421(.006)$ & $.232(.140)$ \\
DCR & & \\
\hline Lathosterol & $.404(.008)$ & $.528(<.001)$ \\
\hline $\begin{array}{l}\text { Lathosterol: } \\
\text { Cholesterol ratio; }\end{array}$ & $.454(.003)$ & $.548(<.001)$ \\
LCR & & \\
\hline Sitosterol & $-.248(.114)$ & $-.273(.080)$ \\
\hline
\end{tabular}

metabolic trait of obesity, increased cholesterol synthesis and decreased cholesterol absorption [18], while SFA is not. This shift in phenotype is reflected by the positive correlation between VFA and VLDL-C and this shift in cholesterol metabolism is not reflected when LDL-C is considered in isolation to guide lipid-lowering therapy.

\section{Discussion}

Our most important finding is the negative correlation between VFA, which independently predicts the development of CAD [1], and LDL-C which is the primary therapeutic target recommended by the ATPIII guidelines for the prevention and treatment of coronary disease. This observation might explain the 'disconnect' between LDL-C and subsequent clinical events which has been observed in patients with diabetes and hypertriglyceridemia $[6,8,11]$. However, VFA was a strong positive correlate of VLDL-C which is predictive of coronary events independently of LDL-C [11]. Non-HDL-C, which for practical purposes is the sum of LDL-C and VLDL-C, did not correlate with VFA or SFA and thus may be more useful in patients with higher degrees of visceral adiposity since it is not spuriously decreased as LDL-C is. VFA correlated negatively with cholestanol, a cholesterol absorption marker and positively with synthesis makers, desmosterol and lathosterol or their ratios. This shift in phenotype with obesity concordant with the positive association between VFA and VLDL-C; an effect that is not captured by isolated consideration of LDL-C. To provide an illustrative example of this, we compared the LDL-C in patients with and without the metabolic syndrome in our cohort. The metabolic syndrome is associated with an increased risk of cardiovascular events in vascular populations similar to ours and 
is therefore a clinically relevant label [19-22]. Patients with the metabolic syndrome in our cohort had greater visceral fat areas $\left(263 \mathrm{vs} 134 \mathrm{~cm}^{2}, \mathrm{P}<0.01\right)$ but lower LDL-C (126 vs $153 \mathrm{mg} / \mathrm{dl}, \mathrm{p}<0.01)$ compared to patients without the metabolic syndrome. Hence patients in our cohort with the metabolic syndrome who are at an increased risk for future cardiovascular events may be incorrectly deemed lower risk by isolated consideration of LDL-C on the standard lipid panel.

Several larger studies have correlated VFA to total cholesterol and have shown both significant positive and negative correlation of total cholesterol and VFA $[4,23]$. However, total cholesterol is no longer the primary target of lipid-lowering therapy. Studies that have related LDL-C to obesity measures such as BMI have also shown both positive and negative associations. While excess body weight has been consistently associated with increases in TG, VLDL-C and decreased HDL-C, the effects of body weight on LDL-C have been variable [24-28]. In our study, the 'gold standard' measure of adiposity, the visceral fat area, in fact showed a negative correlation with LDL-C. The implications of this finding are that high-risk patients with large amounts of visceral adipose tissue may not qualify for drug therapy based on the current ATPIII guidelines, despite being at increased risk for coronary disease [1]. LDL-C has been criticized as an increasingly obsolete therapeutic target in the face of a growing obesity epidemic and nonHDL-C has been proposed as a more appropriate therapeutic target which incorporates the VLDL-C fraction and therefore better capitulates shifting cholesterol metabolism with obesity [6]. In our cohort, non-HDL-C did not correlate significantly with VFA and therefore may be a more appropriate target of therapy than LDL$\mathrm{C}$ that can be applied 'across the board' in both lean and obese individuals. However, since non-HDL-C did not correlate positively with VFA, it is perhaps not the ideal therapeutic target since it did not capture the increased risk associated with increased visceral adipose tissue.

ApoB, which reflects the total number of atherogenic lipid particles, is widely regarded as the 'gold standard' for assessing cardiovascular risk and guiding therapy $[29,30]$. ApoB correlates positively with visceral fat area and may therefore best capture the increased cardiovascular risk with increasing visceral adiposity [23]. ApoB concentrations added to the predictive value of LDL-C in the Quebec Heart Study which was a prospective cohort followed for 13 years [31]. While non-HDL-C was a superior correlate of apoB than LDL-C, there remains some discordance between non-HDL-C and ApoB [32,33]. While non-HDL-C is superior to LDL-C in cardiovascular risk prediction, it may not fully reflect risk associated with the smaller LDL particles which is a hallmark of obesity and insulin resistance [34]. Unfortunately, ApoB assays are not routine in Australia or in many parts of the world and we were unable to assess ApoB in our cohort. On a World-wide basis, the standard lipid panel remains the mainstay of lipid assessment. In this context, non-HDL-C as a therapeutic target may be superior to LDL-C and has the advantage of not being spuriously low in patients with greater amounts of visceral adipose tissue and an increased risk for cardiovascular events.

\section{Acknowledgements}

This work is supported by Pfizer Australia AUS-ATO-06-002 (MRH) and the Royal Brisbane and Women's Hospital Foundation (MRH). MRH receives salary support from the National Health and Medical Research Council of Australia (\#409936). MRH thanks all the vascular surgery staff at the Royal Brisbane \& Women's Hospital for their assistance in identifying eligible patients.

\section{Author details}

${ }^{1}$ Royal Brisbane and Women's Hospital, University of Queensland Centre for Clinical Research, Brisbane, Queensland, Australia. ${ }^{2}$ University of Queensland, Brisbane, Queensland, Australia. ${ }^{3}$ Department of Medical Imaging, Royal Brisbane and Women's Hospital and University of Queensland, Brisbane, Queensland, Australia.

\section{Authors' contributions}

$\mathrm{MRH}$ : designed the study, recruited the patients, primarily extracted the data from the MRI images, analyzed the data and wrote the manuscript. GC, RB and $\mathrm{CM}$ contributed to imaging protocols and imaging acquisition $\mathrm{AC}$ contributed to imaging protocols and supervised patient imaging. All authors read and approved the final manuscript.

\section{Conflicts of interests}

The authors declare that they have no competing interests.

Received: 11 December 2010 Accepted: 19 January 2011 Published: 19 January 2011

\section{References}

1. Fujimoto WY, Bergstrom RW, Boyko EJ, Chen KW, Leonetti DL, NewellMorris L, Shofer JB, Wahl PW: Visceral adiposity and incident coronary heart disease in Japanese-American men. The 10-year follow-up results of the Seattle Japanese-American Community Diabetes Study. Diab Care 1999, 22(11):1808-1812.

2. Yusuf $S$, Hawken $S$, Ounpuu $S$, Bautista L, Franzosi MG, Commerford P, Lang CC, Rumboldt Z, Onen CL, Lisheng L, et al: Obesity and the risk of myocardial infarction in 27,000 participants from 52 countries: a casecontrol study. Lancet 2005, 366(9497):1640-1649.

3. Nieves DJ, Cnop M, Retzlaff B, Walden CE, Brunzell JD, Knopp RH, Kahn SE: The Atherogenic Lipoprotein Profile Associated With Obesity and Insulin Resistance Is Largely Attributable to Intra-Abdominal Fat. Diabetes 2003, 52(1):172-179.

4. Fox CS, Massaro JM, Hoffmann U, Pou KM, Maurovich-Horvat P, Liu CY, Vasan RS, Murabito JM, Meigs JB, Cupples LA, et al: Abdominal visceral and subcutaneous adipose tissue compartments: association with metabolic risk factors in the Framingham Heart Study. Circulation 2007, 116(1):39-48.

5. Miyawaki T, Abe M, Yahata K, Kajiyama N, Katsuma H, Saito N: Contribution of visceral fat accumulation to the risk factors for atherosclerosis in nonobese Japanese. Intern Med 2004, 43(12):1138-1144.

6. Hoenig MR: Implications of the obesity epidemic for lipid-lowering therapy: non-HDL cholesterol should replace LDL cholesterol as the primary therapeutic target. Vasc Health Risk Manag 2008, 4(1):143-156.

7. Grundy SM, Cleeman Jl, Merz CN, Brewer HB Jr, Clark LT, Hunninghake DB, Pasternak RC, Smith SC Jr, Stone NJ: Implications of recent clinical trials for the National Cholesterol Education Program Adult Treatment Panel III guidelines. Circulation 2004, 110(2):227-239. 
8. Cui Y, Blumenthal RS, Flaws JA, Whiteman MK, Langenberg P, Bachorik PS, Bush TL: Non-High-Density Lipoprotein Cholesterol Level as a Predictor of Cardiovascular Disease Mortality. Arch Intern Med 2001, 161(11):1413-1419.

9. Liu J, Sempos C, Donahue RP, Dorn J, Trevisan M, Grundy SM: Joint Distribution of Non-HDL and LDL Cholesterol and Coronary Heart Disease Risk Prediction Among Individuals With and Without Diabetes. Diabetes Care 2005, 28(8):1916-1921.

10. Sachdeva A, Cannon CP, Deedwania PC, Labresh KA, Smith SC Jr, Dai D, Hernandez A, Fonarow GC: Lipid levels in patients hospitalized with coronary artery disease: an analysis of 136,905 hospitalizations in Get With The Guidelines. Am Heart J 2009, 157(1):111-117, e112.

11. Liu J, Sempos CT, Donahue RP, Dorn J, Trevisan M, Grundy SM: Non-highdensity lipoprotein and very-low-density lipoprotein cholesterol and their risk predictive values in coronary heart disease. Am J Cardiol 2006, 98(10):1363-1368.

12. ATPIII: Third Report of the National Cholesterol Education Program (NCEP) Expert Panel on Detection, Evaluation, and Treatment of High Blood Cholesterol in Adults (Adult Treatment Panel III) final report. Circulation 2002, 106(25):3143-3421.

13. MIETTINEN TA, TILVIS RS, KESANIEMI YA: SERUM PLANT STEROLS AND CHOLESTEROL PRECURSORS REFLECT CHOLESTEROL ABSORPTION AND SYNTHESIS IN VOLUNTEERS OF A RANDOMLY SELECTED MALE POPULATION. Am J Epidemiol 1990, 131(1):20-31.

14. Miettinen TA, Tilvis RS, Kesaniemi YA: Serum cholestanol and plant sterol levels in relation to cholesterol metabolism in middle-aged men. Metabolism 1989, 38(2):136-140.

15. Muniyappa R, Lee S, Chen H, Quon MJ: Current approaches for assessing insulin sensitivity and resistance in vivo: advantages, limitations, and appropriate usage. Am J Physiol Endocrinol Metab 2008, 294(1):E15-26.

16. Sarafidis PA, Lasaridis AN, Nilsson PM, Pikilidou MI, Stafilas PC, Kanaki A, Kazakos K, Yovos J, Bakris GL: Validity and reproducibility of HOMA-IR, 1/ HOMA-IR, QUICKI and McAuley's indices in patients with hypertension and type II diabetes. J Hum Hypertens 2007, 21(9):709-716.

17. Chowdhury B, Sjostrom L, Alpsten M, Kostanty J, Kvist H, Lofgren R: A multicompartment body composition technique based on computerized tomography. Int J Obes Relat Metab Disord 1994, 18(4):219-234.

18. Hoenig MR, Kostner KM, Read SJ, Walker PJ, Atherton JJ: Implications of the obesity epidemic for statin therapy: shifting cholesterol metabolism to a high synthesis and low dietary absorption state. Endocr Metab Immune Disord Drug Targets 2007, 7(3):153-166.

19. Vlek AL, van der Graaf Y, Spiering W, Visseren FL: Effect of metabolic syndrome or type II diabetes mellitus on the occurrence of recurrent vascular events in hypertensive patients. J Hum Hypertens 2008, 22(5):358-365.

20. Vlek AL, van der Graaf $Y$, Sluman MA, Moll FL, Visseren FL, Group SS: Metabolic syndrome and vascular risk in patients with peripheral arterial occlusive disease. J Vasc Surg 2009, 50(1):61-69.

21. Wassink AM, Van Der Graaf Y, Soedamah-Muthu SS, Spiering W, Visseren F, Smart Study G: Metabolic syndrome and incidence of type 2 diabetes in patients with manifest vascular disease. Diab Vasc Dis Res 2008, 5(2):114-122.

22. Brevetti G, Laurenzano E, Giugliano G, Lanero S, Brevetti L, Luciano R, Chiariello M: Metabolic syndrome and cardiovascular risk prediction in peripheral arterial disease. Nutr Metab Cardiovasc Dis 2009.

23. Onat A, Avci GS, Barlan MM, Uyarel H, Uzunlar B, Sansoy V: Measures of abdominal obesity assessed for visceral adiposity and relation to coronary risk. Int J Obes Relat Metab Disord 2004, 28(8):1018-1025.

24. Denke MA, Sempos CT, Grundy SM: Excess body weight. An underrecognized contributor to high blood cholesterol levels in white American men. Arch Intern Med 1993, 153(9):1093-1103.

25. Meilahn EN, Kuller LH, Stein EA, Caggiula AW, Matthews KA: Characteristics associated with apoprotein and lipoprotein lipid levels in middle-aged women. Arteriosclerosis 1988, 8(5):515-520.

26. Foster CJ, Weinsier RL, Birch R, Norris DJ, Bernstein RS, Wang J, Pierson RN, Van Itallie TB: Obesity and serum lipids: an evaluation of the relative contribution of body fat and fat distribution to lipid levels. Int J Obes 1987, 11(2):151-161.

27. Jacobs DR Jr, Burke GL, Liu K, Cutter G, Hughes G, Hulley S, Sidney S: Relationships of low density lipoprotein cholesterol with age and other factors: a cross-sectional analysis of the CARDIA study. Ann Clin Res 1988, 20(1-2):32-38

28. Denke MA, Sempos CT, Grundy SM: Excess body weight. An underrecognized contributor to dyslipidemia in white American women. Arch Intern Med 1994, 154(4):401-410.

29. Sniderman AD, Furberg CD, Keech A, Roeters van Lennep JE, Frohlich J, Jungner I, Walldius G: Apolipoproteins versus lipids as indices of coronary risk and as targets for statin treatment. Lancet 2003, 361(9359):777-780.

30. Walldius G, Jungner I, Holme I, Aastveit AH, Kolar W, Steiner E: High apolipoprotein B, low apolipoprotein A-I, and improvement in the prediction of fatal myocardial infarction (AMORIS study): a prospective study. The Lancet 2001, 358(9298):2026-2033.

31. St-Pierre AC, Cantin B, Dagenais GR, Despres JP, Lamarche B: Apolipoprotein-B, low-density lipoprotein cholesterol, and the long-term risk of coronary heart disease in men. Am J Cardiol 2006, 97(7):997-1001.

32. Ballantyne CM, Andrews TC, Hsia JA, Kramer JH, Shear C: Correlation of non-high-density lipoprotein cholesterol with apolipoprotein B: effect of 5 hydroxymethylglutaryl coenzyme A reductase inhibitors on non-highdensity lipoprotein cholesterol levels. Am J Cardiol 2001, 88(3):265-269.

33. Barter PJ, Ballantyne CM, Carmena R, Castro Cabezas M, Chapman MJ, Couture P, de Graaf J, Durrington PN, Faergeman O, Frohlich J, et al: Apo B versus cholesterol in estimating cardiovascular risk and in guiding therapy: report of the thirty-person/ten-country panel. J Intern Med 2006, 259(3):247-258.

34. Sniderman AD, St-Pierre AC, Cantin B, Dagenais GR, Despres JP, Lamarche B Concordance/discordance between plasma apolipoprotein B levels and the cholesterol indexes of atherosclerotic risk. Am J Cardiol 2003, 91(10):1173-1177.

doi:10.1186/1476-511X-10-12

Cite this article as: Hoenig et al:: Low density lipoprotein cholesterol is inversely correlated with abdominal visceral fat area: a magnetic resonance imaging study. Lipids in Health and Disease 2011 10:12.

\section{Submit your next manuscript to BioMed Central and take full advantage of:}

- Convenient online submission

- Thorough peer review

- No space constraints or color figure charges

- Immediate publication on acceptance

- Inclusion in PubMed, CAS, Scopus and Google Scholar

- Research which is freely available for redistribution

Submit your manuscript at www.biomedcentral.com/submit
C Biomed Central 